\title{
Bone remodeling around implants placed after socket preservation: a 10-year retrospective radiological study
}

\author{
Crespi Roberto ${ }^{1,2^{*}}$, Toti Paolo ${ }^{1,2}$, Crespi Giovanni ${ }^{2}$, Covani Ugo ${ }^{1,2}$, Brevi Bruno ${ }^{3}$ and \\ Menchini-Fabris Giovanni-Battista ${ }^{1,2}$
}

\begin{abstract}
Background: To evaluate and compare the long-term clinical and radiological outcomes of post-extraction sockets after ridge preservation either with porcine xenograft or collagen alone. Patients underwent single-tooth extraction in the posterior mandible. Fresh extraction sockets were filled with pre-hydrated cortico-cancellous porcine bone or collagen sponge. Two or 3 months later, a ridge expansion technique with immediate implant positioning placement was performed. Primary (alveolar width changes) and secondary outcomes (adverse events and longterm maintenance of buccal plate covering the implant) were evaluated.

Results: Thirty-four women and 20 men were selected: 30 implants (group A) placed into healed post-extraction sockets grafted with porcine bone and 24 (group B) into sockets filled with a collagen sponge. There was a significant loss in width in both groups from the first and second surgery (ranging between $2.7 \mathrm{~mm}$ and $4.5 \mathrm{~mm}$ ). The ridge splitting with bone expansion resulted in significant long-term increases in width for both procedures and implant sites. Non-significant differences in alveolar width were registered between the groups at 10-year follow-up even if the analysis of the implant buccal bone coverage suggested that group A had significantly worst results.
\end{abstract}

Conclusions: Porcine bone group had significantly better short-term outcomes with lower long-term maintenance of the buccal plate.

Keywords: Alveolar ridge preservation, Split crest procedure, Xenogeneic bone substitute, Collagen sponge, Dental implants

\section{Background}

Considerable difficulties in positioning dental implants in fresh extraction sockets could be associated with gradual loss of height of the alveolar walls or damage of the buccal bone plate, especially in the anterior maxilla region where the maintenance of sufficient bone volume allowed for achieving the best results in

\footnotetext{
*Correspondence: editorial.activities@istitutostomatologicotoscano.it ${ }^{1}$ School of Dentistry, Saint Camillus International University of Health and Medical Sciences, Via di Sant'Alessandro, 8, 00131 Rome, Italy ${ }^{2}$ Department of Stomatology, Tuscan Stomatological Institute, c/o Versilia General Hospital, via Aurelia 335, 55049 |Lido di Camaiore, Italy Full list of author information is available at the end of the article
}

terms of biological and aesthetic outcomes [1-4]. It is therefore not surprising that several surgical procedures, such as guided bone regeneration $[5,6]$, or grafting augmentation procedures with or without autologous bone which could be substituted with any bone replacing material (such as allogeneic, xenogeneic, or synthetic bone substitutes) [7-9] were recommended to maintain the volume of the alveolar process during the healing phase.

Due to their excellent biocompatibility and bioactivity, anorganic animal bone particles were used as graft materials for both the ridge preservation and the maxillary sinus augmentation, so providing sufficient gain to 
achieve adequate bone volume and quality [10-13]. Nevertheless, some synthetic materials were tested, the porcine bone, used for socket filling after tooth extraction, seemed to behave in a similarly in the histological pattern and bone remodeling process [14, 15]. Meanwhile, it was assessed the advance in increasing the bone mineral content of the buccal bone defects after filling with collagen alone [16].

\section{Methods}

The present study aimed to compare and evaluate the clinical and radiological outcomes of delayed implant placement in healed extraction sockets previously grafted with cortico-cancellous porcine bone versus sockets filled by collagen alone. The study reported long-term findings at 10 years.

\section{Patient selection}

In a retrospective analysis, all subjects were selected among a cohort of patients who were consecutively treated between January 2008 and June 2010 at Tuscan Stomatological Institute and followed up at the Complex Operating Unit of Maxillo-Facial Surgery of the University of Pisa. This study followed the Declaration of Helsinki on medical protocol and ethics, and the regional Ethical Review Board of the University of Pisa approved the present analysis.

Only patients matching the following criteria were included in the further data analysis: patients who signed an informed consent form (18 years old or older); single tooth extraction in the posterior area; alveolar ridge/socket preservation (ARP) in posterior extraction sites with either a cortico-cancellous porcine bone or a collagen sponge; delayed alveolar ridge-splitting/expansion (ARS) technique with immediate dental implant placement; report of a clinical follow-up period up to 10 years from the first surgery; preoperative (baseline 1) and postoperative (baseline 2 and 10 years) mandibular computerized tomography scans as well as displayed in the diagram (Fig. 1) describing the chronology of surgical interventions and of investigations at different points in time.

Patients were excluded if any of the following items were shown in the medical records: history of chronic and systemic diseases coming out during follow-up that contraindicate oral surgery; long-term nonsteroidal anti-inflammatory drug therapy; oral or intravenous administration of bisphosphonate drugs; heavy smokers with a cigarette consumption higher than 10 cigarettes/day.

\section{Surgery}

One hour before surgery, each patient received prophylactic therapy $(1 \mathrm{~g}$ of amoxicillin or clindamycin $600 \mathrm{mg}$ if allergic to penicillins, then $1 \mathrm{~g}$ amoxicillin or $300 \mathrm{~g}$ clindamycin twice daily for 5 days. All patients were treated under local anesthesia using optocaine $20 \mathrm{mg} /$ $\mathrm{mL}$ with adrenaline $1: 100,000$. According to the basic steps of the "socket-plug" technique teeth were extracted without flap elevation to maximally preserve the hard and soft tissues, avoiding periosteum detachment and traumatic tooth extraction.

In group $\mathrm{A}$, extraction sockets were grafted up to the buccal and palatal margin of the alveolar wall with a pre-hydrated cortico-cancellous porcine bone (particle size between 600 and $1000 \mu \mathrm{m}, \mathrm{MP3}$, OsteoBiol ${ }^{\circ}$, Tecnoss ${ }^{\circ}$, Coazze, Italy). Subsequently, a collagen sheet (Condress ${ }^{\oplus}$, Abiogen Pharma, Pisa, Italy) was placed to cover the socket, and secured with silk sutures [14] to

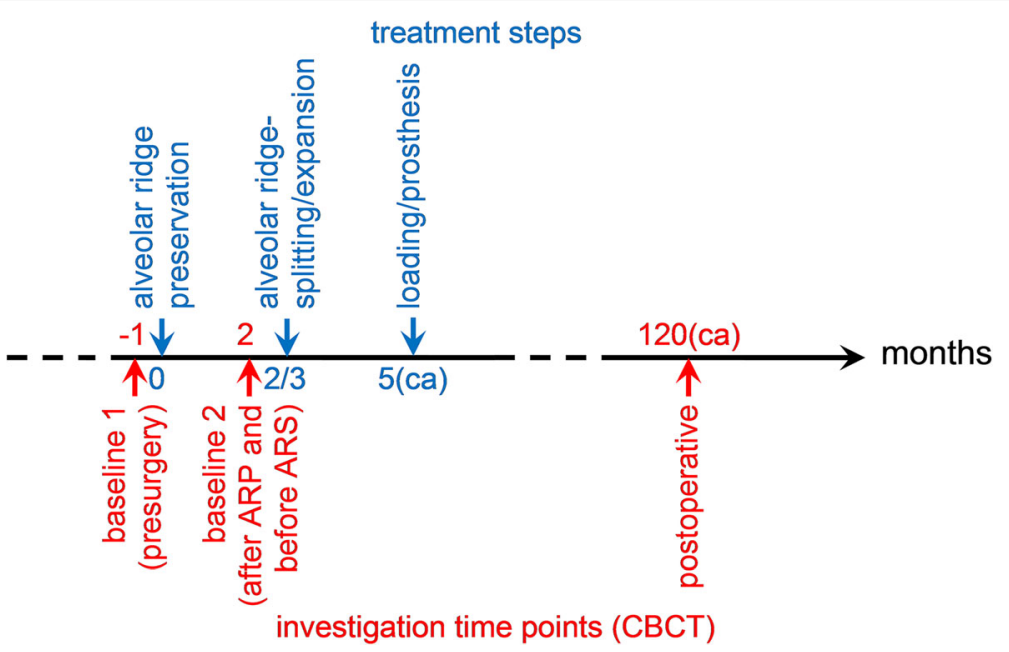

Fig. 1 Scheme for chronology of surgical interventions and of investigations at different points in time 


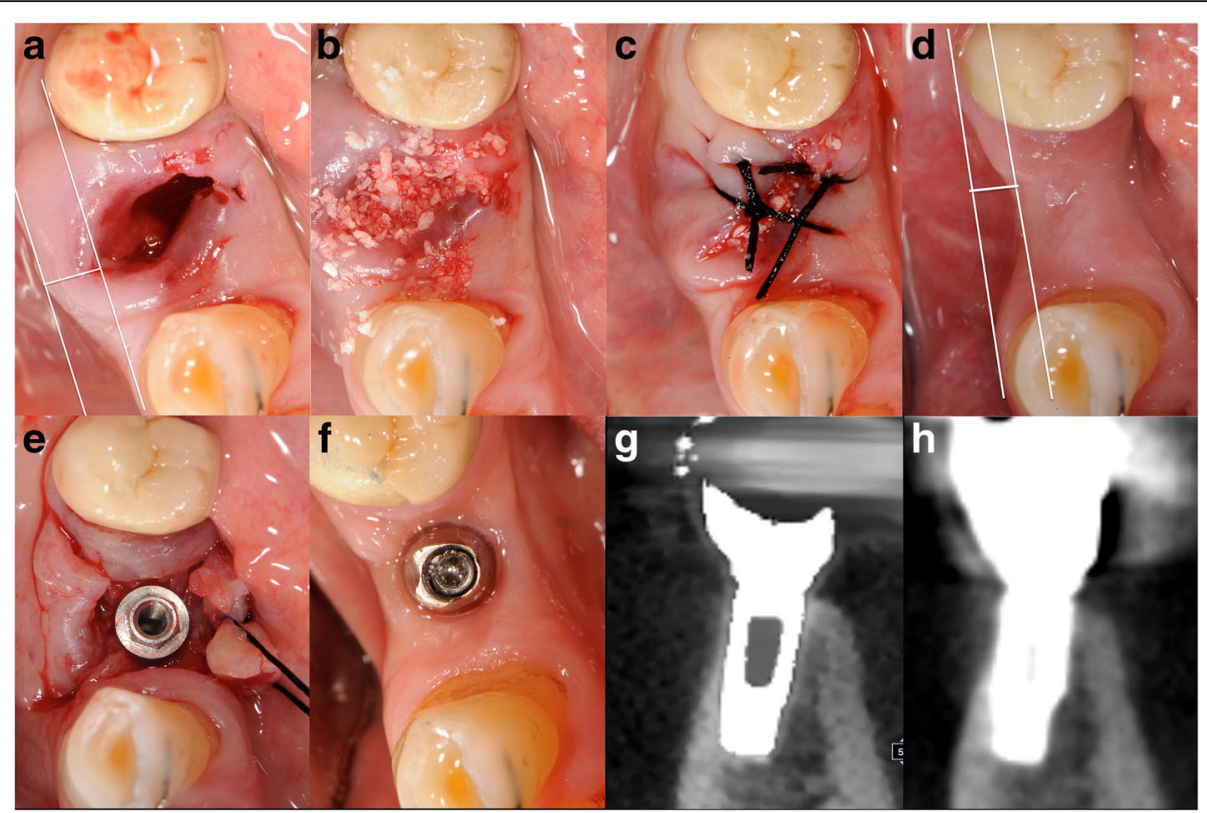

Fig. 2 Clinical photographs. a fresh socket; b cortico-cancellous porcine and filled socket; c collagen sheet covering secured with silk sutures; d site healing at 3 months; $\mathbf{e}$ implant placement into healed site; $\mathbf{f}$ healed site; $\mathbf{g}$ cone beam computed tomography 3 years after implant placement and $\mathbf{h}$ after 10 years from first surgery 1

stabilize blood clots and to prevent the leakage of graft particles (Fig. 2a-c).

In group $\mathrm{B}$, the extraction sockets were filled with collagen sponges. If sutures were placed, they stabilized the collagen [16]. The sutures were not tight without primary closure of the wound [16]. The wound was left to heal by secondary intention (Fig. 3a-c).

In both groups 8-10 weeks after surgery (Fig. 2d; Fig. 3d), an alveolar ridge expansion was performed by an electromagnetic device (Magnetic Mallet, www. osseotouch.com, Turbigo, Milano, Italy) [17]. A palatal or lingual incision in crestal direction was performed followed by two transperiosteal incisions made perpendicular to the initial incision on either side allowing the raising of a partial-thickness flap. After the flap reflection, two vertical grooves were made by the penetration of the vestibular cortical bone plate one on the mesial aspect and one on the distal aspect of the flap edges by keeping a safe distance of $1 \mathrm{~mm}$ from the adjacent teeth (Fig. 2e). A blade directly attached to the electromagnetic device performed the crestal bone incision maintaining a zone of spongy bone beneath the cortical plate with a minimum thickness of $1.5 \mathrm{~mm}$ and penetrated the alveolar ridge from 7 to $11 \mathrm{~mm}$ deep. The bony wall was slowly expanded and the facial bony plate was dislocated in a buccal direction with a progressive series of bone expanders attached to the handpiece of the electromagnetic device.

The recipient site was prepared undersized by $1 \mathrm{~mm}$ than the implant diameter in the newly created space obtained by expanding the bone tissue both laterally, against the preexisting lateral walls, and apically, moving up and compressing it. Titanium Plasma Spray implants with a machined neck for $0.8 \mathrm{~mm}$, and a rough surface, body with a progressive thread design (Seven, Sweden and Martina, Padua, Italy), were firmly seated with native bone engagement (Fig. 2e; Fig. 3e, f).

The buccal flap was apically repositioned, sutured to the margin of the palatal/lingual flap, and anchored with a loose loop to the periosteum at the level of the alveolar mucosa. The surgical field was covered by collagen that was inserted under the undermined keratinized mucosa that lined the flap edges. The collagen ensured that the bleeding stops and intended to stabilize the blood clot [18].

\section{Prosthetic protocol}

After 2 months of submerged healing, dental implants were loaded (Fig. 2f; Fig. 3g) with two different polyvinylsiloxanes impression materials (Flexitime Heavy plus Flow, Heraeus/Kulzer, Milan, Italy) with an individual acrylic impression tray. The final crown restoration was applied onto custom abutment. After a temporary crown restoration, definitive ceramic fused-to-metal restoration was fabricated 5 months after the first surgery (Fig. $2 \mathrm{~g}$, h; Fig. 3h).

\section{Primary predictors}

Group A: pre-hydrated cortico-cancellous porcine bone Group B: collagen sponge 


\section{Secondary predictors}

Patient gender and implant site

\section{Radiographic examination and outcome variables}

Computerized tomographic scans were acquired with a device dedicated to dental and maxillofacial imaging (Gendex GXCB-500; Gendex Dental Systems Hatfield, PA, USA) with the following setting: $120 \mathrm{kV}, 30.89 \mathrm{mAs}$, $200 \mu \mathrm{m}$ isotropic voxel, $8.5 \mathrm{~cm}$ field of view (FOV). The CBCT scans of each patient were then transferred to a single-blind examiner radiologist for evaluation which performed all the measurements.

Preoperative and postoperative scans were modified appearing to be superimposable according to Crespi and co-workers [19]. CBCT cross-sectional images were extrapolated from each set of the three scans superimposed in the space (using a triangulation of point data: two spines of Spix and midpoint of the segment connecting the two mental foramina). Measurement of the alveolar width (AW) was performed in a cross-sectional image that passed through the long axis of the implant and along a line perpendicular to it passing between the most coronal points of the palatal bone level and the most prominent point of the buccal bone. The position of the implant served as the point of reference for the preoperative superimposed measurements. The loss in bone width $(\triangle \mathrm{AW})$ was given by Equation 1: $\triangle \mathrm{AW}=$ $A W_{\text {postop }}-\mathrm{AW}_{\text {preop }}$ (Eq. 1)

Maintenance of the buccal plate was measured on the above-mentioned cross-sectional image at 10 years of follow-up; it was assessed with a dichotomic value (yes/no).

In particular, the blind measurer relied on the subjective criterium such as "cutoff of at least $70 \%$ or more percentage of bone/implant coverage at the buccal side."

\section{Statistical analysis}

A specific program dedicated to statistics (Statistics Toolbox, MATLAB 7.11; The MathWorks) was employed for all the analyses. Normal distributions of groups and subgroups were not confirmed, so sample description, dispersion, and analysis used a nonparametric approach. Bone width values were reported as a median and interquartile range, $\tilde{m}$ (iqr) and rounded to the nearest decimal.

The Null hypothesis: H0, there was no difference when healed posterior mandibular site underwent alveolar ridge preservation with socket-plug technique (pre-hydrated cortico-cancellous porcine bone substitute versus collagen sponge alone) was treated by ridge splitting and simultaneous implant placement.

Friedman's test has been employed as a nonparametric analysis of variance test (ANOVA). To compare the differences between radiographic values between groups at every time point, post-hoc pair-wise comparisons were performed by Mann-Whitney tests for independent samples. Differences between times were evaluated with the Wilcoxon signed-rank test. The significance was set at a level of 0.01 .

\section{Results}

\section{Clinical outcomes}

Fifty-four subjects, 34 women and 20 men (with a mean age of $53.8 \pm 7.1$ years with a range from 41.8 to 69.1 years) were selected. A single tooth per patient was analyzed, thus bringing the number of dental implants with delayed placement to $54: 30$ implants in group A were placed in preserved post-extraction sockets grafted with a porcine bone; 24 implants belonging to group B were placed in preserved post-extraction sockets filled with a collagen sponge alone. During the healing period, neither soft tissue infection episodes nor signs of exposed bone were mentioned in the case sheets attesting to the achievement of complete wound healing around the temporary restoration.

\section{Radiographic evaluation}

Absolute values of the alveolar bone widths (AWs) and their changes in time $(\triangle \mathrm{AW})$ were shown in Table 1. The site of the implant, i.e., bicuspid versus molar, had been checked to test the influence of the variance in the alveolar width change between the two groups with regard to this confounding factor. On the other side, the Friedman tests did not reveal any significant influence on the changes between the genders (Table 1).

The intragroup analyses suggested that significant width reductions of the alveolar processes were observed in both groups from baseline 1 to baseline 2 , that is about $2 / 3$ months after the alveolar ridge preservation and before the dental implant placement, with a loss ranging between -2.7 and $-4.6 \mathrm{~mm}$. This proved that, at least in the molar region, the alveolar ridge preservation technique with low absorption material should fulfill its purposes exactly matching the expectations of the clinician.

The radiological outcome of the alveolar ridge expansion procedure, measured from baseline 2 to 10 years, showed a significant increase in the alveolar width in both groups (A and B) and sites (bicuspid and molar); in fact, significant increases in width (ranging from +1.0 $\mathrm{mm}$ to $+1.9 \mathrm{~mm}$ with $p$ values $\leq 0.0009)$ were still visible after a decade.

Cross-group analyses suggested that loss in the alveolar width was higher in group B than in group A at least until the second surgery, i.e., alveolar ridge expansion (2/3 months after) for both implant sites.

Changes in alveolar width, albeit not significant in the premolar sites, ranged from 9.8(0.7) to 7.1(1.3) $\mathrm{mm}$ and from $10.2(0.8)$ to $6.7(0.7) \mathrm{mm}$ for group $\mathrm{A}$ and $\mathrm{B}$, 
Table 1 Median and interquartile range $\tilde{m}$ (iqr) of the alveolar bone width at baseline 1 (pre-extraction) and baseline 2 (before delayed dental implant placement) and after 10 years for sites with porcine bone graft (A) and collagen sponge (B)

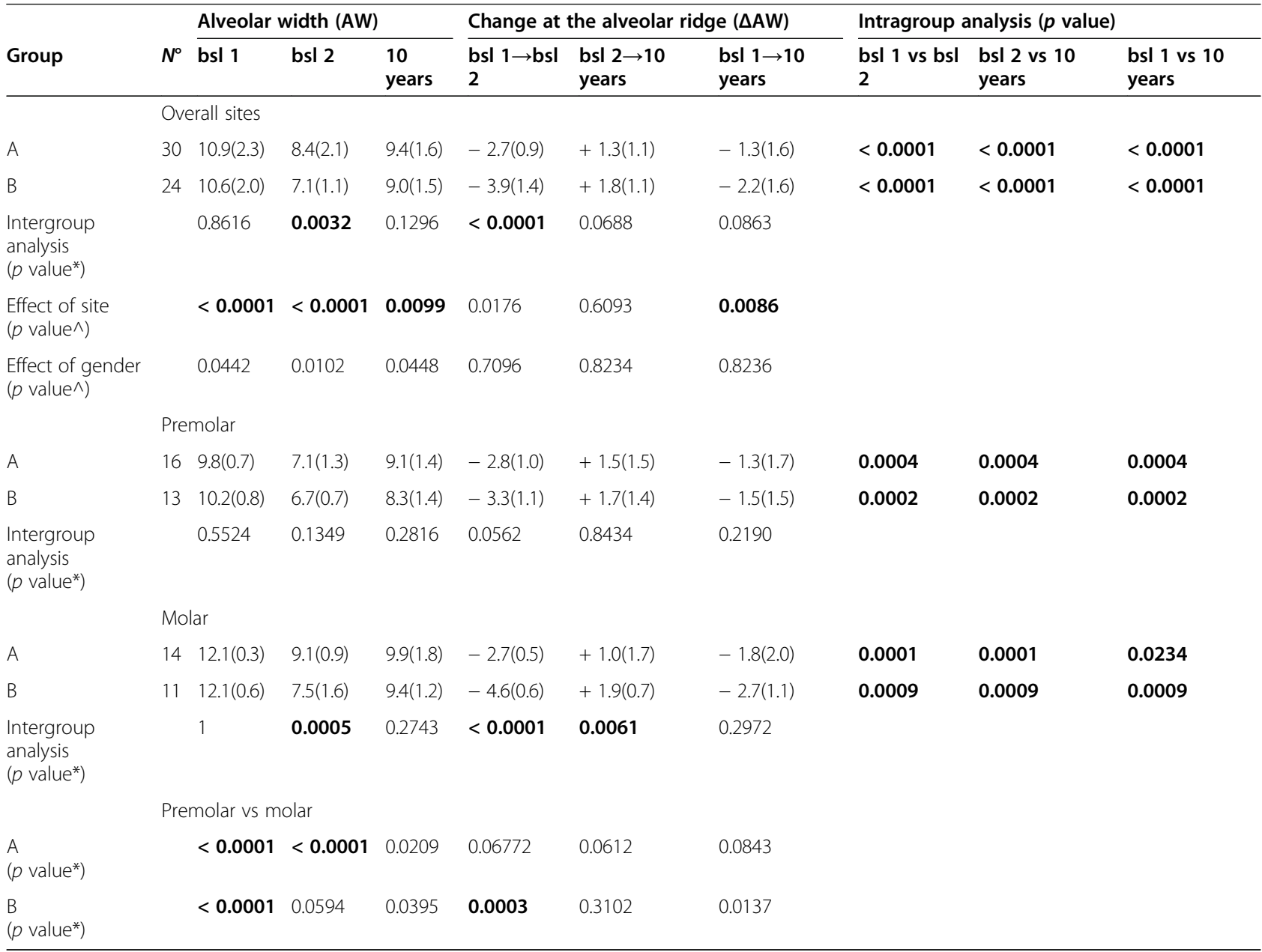

Results with significance in bold

$\wedge$ Non-parametric analysis of variance test (ANOVA Friedman test)

*Mann-Whitney tests

${ }^{\circ}$ Wilcoxon signed-rank test

respectively; on the contrary, they significantly changed from 12.1(0.3) to $9.1(0.9) \mathrm{mm}$ and from 12.1(0.6) to 7.5(1.6) $\mathrm{mm}$ for group $\mathrm{A}$ and $\mathrm{B}$, respectively, in the molar site.

Again, changes in the molar area indicated that alveolar ridge expansion led to an overall and statistically significant higher increase $(p=0.0061)$ in group $\mathrm{B},+1.9$ $(0.7 \mathrm{~mm}$, than that reported in group $\mathrm{A},+1.0(1.7) \mathrm{mm}$. Furthermore, the remodeling process after tooth avulsion and before dental implant placement (2/3 months after ridge preservation) demonstrated that the premolar regions behaved significantly different (with $p=0.0003$ ) when compared to the molar ones, even if for the extraction sockets filled with collagen sponges.

Finally, no significant differences were registered at 10-year follow-up between the two procedures and between the two implant sites (Table 1).
Overall radiologic outcomes (from baseline 1- to 10year survey) calculated summing over time the changes in alveolar width after both surgeries (ARP and ARS) showed no significant differences between the group A and $\mathrm{B}$.

The outcomes regarding the buccal contours demonstrated that few implants in group B ( 2 out of 24 placed in sockets preserved with collagen alone) had no complete buccal bone coverage, as visible in the CBCT images and segmentations. Moreover, the analysis of the distribution of the data (Table 2) demonstrated that group A showed significantly worst results over the long term than group B (Fisher's exact test $p$ value $=0.0005$ ).

\section{Discussion}

The present analysis aimed to understand how different bone substitutes with different rates of resorption 


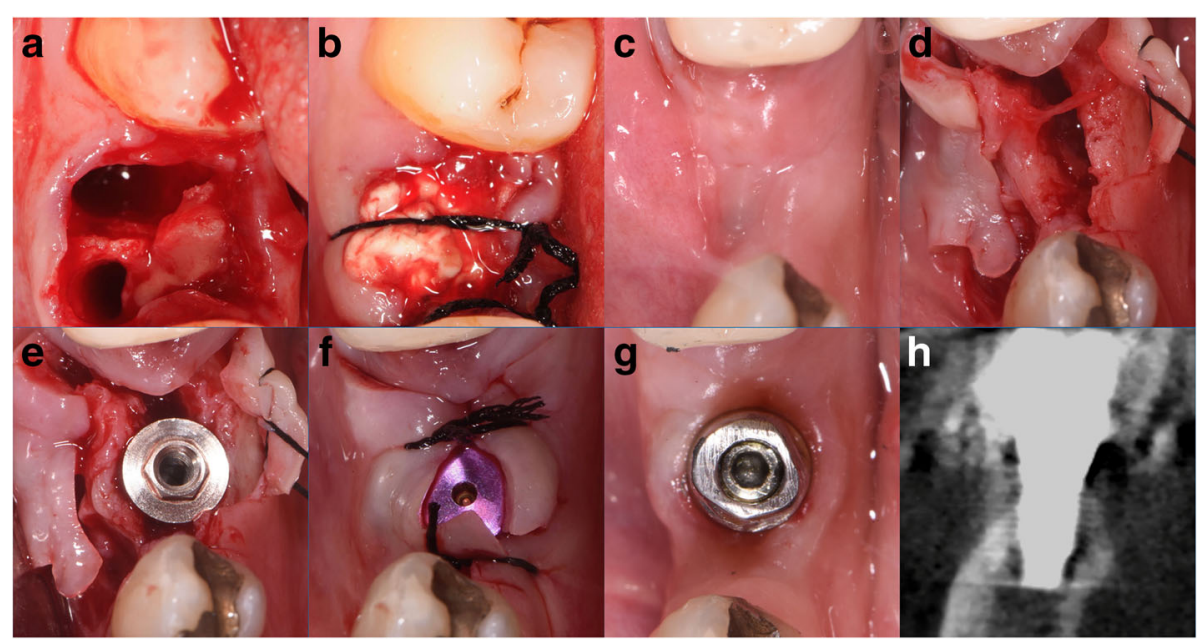

Fig. 3 Clinical photographs: a fresh socket; $\mathbf{b}$ collagen filling the socket; $\mathbf{c}$ site healing at 3 months; $\mathbf{d}$ site after split crest; e implant placed; $\mathbf{f}$ site secured with silk sutures; $\mathbf{g}$ healed site; $\mathbf{h}$ cone beam computed tomography after 10 years from first surgery

(xenogeneic cortico-cancellous bone or collagen sponge) used in alveolar ridge preservation could affect longterm changes in alveolar width when socket preservation was combined with delayed alveolar ridge splitting/expansion technique and immediate implant placement.

As far as bone remodeling is concerned, the type of surgical procedure (traumatic/atraumatic) is one of the most active factors: the architecture of the tissues around the surgical site (hard and soft tissues) and dynamic of the healing process (wound closure and blood clot stabilization) were key drivers for success [20]. Among the several strategies used to prevent alveolar bone resorption, different methods of ridge preservation had been proposed, that range from atraumatic flapless tooth extraction aiming for undisturbed extraction wounds [21] to more complex and demanding socketplug technique in combination with different grafting materials, barrier membranes, and additional surgical procedures [22].

Computerized tomography scans acquired immediately after extraction and then at 3 months after surgery revealed that sockets treated with porcine bone demonstrated a loss of less than $25 \%$ in width of the alveolar ridge. On the contrary, sockets filled with collagen sponge showed a significantly higher shrinkage dimension (about 35\%) than that registered for group A. This could lead to the conclusion that the patients benefit from receiving grafting materials at the time of tooth extraction. Even if the present procedure seemed to be more demanding than the standard ones of the other authors, Jung and co-workers [23] attested that the xenogeneic bone substitutes appeared to be able to limit, up to a certain extent, the resorption of the alveolar process after tooth extraction; this was confirmed also in the present study where both groups (porcine bone and collagen alone) showed a dimensional shrinkage before the dental implant was placed. Furthermore, Ten Heggeler and co-workers [24] confirmed that alveolar ridge preservation utilizing the "socket-plug" technique may not prevent the physiological resorption of the alveolar bone, especially in molar areas. However, in the present study the healing pattern of extraction sockets preserved using collagen sponges seemed to have a behavior similar to that reported by Chen and co-workers [25], and by Amler [26]; the above-mentioned authors confirmed that two-thirds of the sockets appeared to be filled with the mineralized bone after only 40 days of healing.

The results achieved through the use of the collagen tablets [27] might explain the similar clinical outcomes reported in this study for the first 8-10 weeks in which socket healing moved through three fundamental phases: the first one-remodeling of the blood

Table 2 Distribution about maintenance of the buccal bone plate at 10 years of follow-up for the porcine bone graft group (A) and collagen sponge group (B)

\begin{tabular}{llll}
\hline & Buccal bone maintenance & Buccal bone resorption & Fisher's exact test \\
\hline A & 14 & 16 & 0.0005 \\
B & 22 & 2 & \\
\hline
\end{tabular}


clot within a week after tooth extraction, the second-consistent deposition of temporary connective tissue within the first weeks of healing, and finally, laying down of the bony matrix and its mineralization in a less predictable time.

The ridge expansion technique led to an increase in the alveolar width that persisted to the last survey for both groups with a significantly higher augmentation in sockets filled with collagen than those grafted with porcine bone. Radiographic analysis of the collagen-grafted sites here reported, suggested that outcomes were similar to those described in previous studies, where new bone formation around implants placed in augmented bone in which reactive soft tissue was left in the defects had been evaluated using cone-beam computerized tomography (CBCT) [28, 29]. However, short-term crosssectional images (not selected for the analysis) revealed that maintenance of buccal plate was similar in both groups; on the contrary, at the final check-up for radiologic evaluation differences were registered. Trend about the bone remodeling was confirmed by the maintenance of the buccal cortical plate around dental implants placed in the sites grafted with collagen (22 out of 24) but not in the areas treated with the porcine bone substitute; several cases of buccal cortical plate loss were registered.

A significant difference between the two groups might be explained by the steady-state bone remodeling activity of the peri-implant tissues which acted to balance the functional strengths and reaction of supporting tissues; so, a positive remodeling of the bone was a simple response to mechanical stress [30]. Bone substitute materials underwent volume resorption and complete replacement by new vital bone in a very long time (it could take more than 4 years); however, currently, from a clinical point of view, there was no evidence that the load-bearing capacity of augmented bone appeared to be different compared with the normal bone [31].

\section{Conclusions}

The porcine bone group had significantly better shortterm outcomes with lower long-term maintenance of the buccal cortical plate around dental implants. On the contrary, the collagen allowed the formation and preservation of the buccal cortical plate.

\footnotetext{
Abbreviations

ARP: Alveolar ridge/socket preservation; ARS: Alveolar ridge-splitting/expansion; FOV: Field of view; AW: Alveolar width; $\triangle \mathrm{AW}$ : Change in alveolar width; CBCT: Cone beam computerized tomography

\section{Acknowledgements}

None

\section{Authors' contributions}

Conceptualization, G.B.M.-F., P.T., and R.C.; methodology, G.B.M.-F., G.C., B.B., and R.C.; software, P.T.; validation, G.C., U.C., B.B., and R.C.; formal analysis, P.T.
}

and G.C.; investigation, U.C. and R.C.; resources, R.C.; data curation, G.C., U.C. B.B., and R.C.; writing original draft preparation, G.B.M.-F., P.T., and R.C.; writing - review and editing, G.C., U.C., B.B., and R.C.; visualization, G.B.M.-F. and P.T.; supervision, R.C.; project administration, U.C. and R.C.; funding acquisition, R.C.; final approval G.B.M.-F., P.T., G.C., U.C., B.B., and R.C.; agreement to be accountable for all aspects of the work, G.B.M.-F., P.T., G.C., U.C., B.B., and R.C. All authors have read and agreed to the published version of the manuscript.

\section{Funding}

No external funding was available for this study.

\section{Availability of data and materials}

The datasets used and/or analyzed during the current study are available from the corresponding author on reasonable request in STRUCT form with multiple strings/arrays running in MATLAB version 7.01 or later.

\section{Declarations}

\section{Ethics approval and consent to participate}

Patients had to sign a routine informed consent form regarding surgical treatment, and additional informed consent for analysis of their data, as requested by the ethical committee according to Helsinki Declaration (1975) and further revisions. All procedures performed in studies involving human participants are in accordance with the ethical standards of the institutional and/or national research committee (Local Ethical Committee of the University of Pisa for retrospective analysis 2626-2008 PROT n 58183).

\section{Consent for publication}

Not applicable

\section{Competing interests}

The authors declare that they have no competing interests.

\section{Author details}

${ }^{1}$ School of Dentistry, Saint Camillus International University of Health and Medical Sciences, Via di Sant'Alessandro, 8, 00131 Rome, Italy. ${ }^{2}$ Department of Stomatology, Tuscan Stomatological Institute, c/o Versilia General Hospital, via Aurelia 335, 55049 |Lido di Camaiore, Italy. ${ }^{3}$ Department of Maxillo-Facial Surgery, Hospital and University of Pisa, via Paradisa 2, Pisa 56124, Italy.

Received: 24 February 2021 Accepted: 5 May 2021

Published online: 29 July 2021

\section{References}

1. Araujo MG, Lindhe J. Dimensional ridge alteration following tooth extraction. An experimental study in the dog. J Clin Periodontol. 2005;32(2): 212-8. https://doi.org/10.1111/j.1600-051X.2005.00642.x.

2. Hurzeler MB, Kohal RJ, Naghshbandi J, et al. Evaluation of a new bioresorbable barrier to facilitate guided bone regeneration around exposed implant threads. An experimental study in the monkey. Int J Oral Maxillofac Surg. 1998;27(4):315-20. https://doi.org/10.1016/S0901-502 7(05)80623-X.

3. Okamoto T, Onofre Da Silva A. Histological study on the healing of rat dental sockets after partial removal of the buccal bony plate. J Nihon Univ Sch Dent. 1983;25(3):202-13. https://doi.org/10.2334/josnusd1959.25.202.

4. Sclar AG. Strategies for management of single-tooth extraction sites in aesthetic implant therapy. J Oral Maxillofac Surg. 2004;62(Suppl 2):90-105. https://doi.org/10.1016/j.joms.2004.06.041.

5. Becker W, Dahlin C, Becker BE, Lekholm U, van Steenberghe D, Higuchi K, et al. The use of e-PTFE barrier membranes for bone promotion around titanium implants placed into extraction sockets: a prospective multicenter study. Int J Oral Maxillofac Implants. 1994;9(1):31-40.

6. Nevins M, Mellonig J. Enhancement of damaged edentulous ridge to receive dental implants: A combination of allografts and the Gore-Tex membrane. Int J Periodontics Restorative Dent. 1992;12:97-111.

7. Cammack GV II, Nevins M, Clem DS III, et al. Histologic evaluation of mineralized and demineralized freeze-dried bone allograft for ridge and sinus augmentations. Int J Periodontics Restorative Dent. 2005;25(3):231-7. 
8. Artzi Z, Tal H, Dayan D. Porous bovine bone mineral in healing of human extraction sockets. Part I. Histomorphometric evaluation at 9 months. J Periodontol. 2000;71(6):1015-23. https://doi.org/10.1902/jop.2000.71.6.1015.

9. Benque EP, Gineste $M$, Heughebaert $M$. Histological study of the biocompatibility of hydroxyapatite crystals in periodontal surgery. J Biol Buccale. 1985;13(4):271-82.

10. Valentini $P$, Abensur DJ. Maxillary sinus grafting with anorganic bovine bone: a clinical report of long-term results. J Oral Maxillofac Surg. 2003;18: 556-60.

11. Hallman M, Sennerby L, Lundgren S. A clinical and histologic evaluation of implant integration in the posterior maxilla after maxillary sinus floor augmentation with bovine hydroxyapatite and autogenous bone. J Oral Maxillofac Surg. 2002;60(3):277-84. https://doi.org/10.1053/joms.2002.30576.

12. Tapety Fl, Amizuka N, Uoshima K, et al. A histological evaluation of the involvement of Bio-Oss ${ }^{\oplus}$ in osteoblastic differentiation and matrix synthesis. Clin Oral Implants Res. 2004;29:315-24.

13. Barone A, Crespi R, Aldini NN, Fini M, Giardino R, Covani U. Maxillary sinus augmentation with heterologous bone:histologic and histomorphometric analysis. Int J Oral Maxillofac Implants. 2005;20(4):519-25.

14. Crespi R, Capparè P, Gherlone E. Magnesium-enriched hydroxyapatite compared with porcin bone in human extraction socket healing: a histologic and histomorphometric evaluation. Int J Oral Maxillofac Implants. 2011;26(5):1057-62.

15. Gholami GA, Najafi B, Mashhadiabbas F, Goetz W, Najafi S. Clinical, histologic and histomorphometric evaluation of socket preservation using a synthetic nanocrystalline hydroxyapatite in comparison with a bovine xenograft: a randomized clinical trial. Clin Oral Implants Res. 2012;23(10):1198-204. https://doi.org/10.1111/j.1600-0501.2011.02288.x.

16. Crespi $R$, Capparè $P$, Gherlone EF. Bone recountoring in fresh sockets with buccal bone loss. a cone beam ct study. Int J Oral Maxillofac Implants. 2014; 29(4):863-8. https://doi.org/10.11607/jomi.3506.

17. Bruschi GB, Capparè $P$, Bravi F, et al. Radiographic evaluation of crestal bone level in split-crest and immediate implant placement: minimum 5-year follow-up. Int J Oral Maxillofac Implants. 2017;32(1):114-20. https://doi.org/1 $0.11607 /$ jomi.4203.

18. Scipioni A, Bruschi GB, Calesini G. The edentulous ridge expansion technique: a five year study. Int J Periodontics Restorative Dent. 1994;14(5): 451-9.

19. Crespi R, Menchini Fabris GB, Crespi G, et al. Effects of different loading protocols on the bone remodeling volume of immediate maxillary single implants: A 2- to 3-year follow-up. Int J Oral Maxillofac Implants. 2019;34(4): 953-62. https://doi.org/10.11607/jomi.6972.

20. Kotsakis G, Chrepa V, Marcou N, Prasad H, Hinrichs J. Flapless alveolar ridge preservation utilizing the "socket-plug" technique: clinical technique and review of the literature. J Oral Implantol. 2014;40(6):690-8. https://doi.org/1 0.1563/AAID-JOI-D-12-00028.

21. Fickl S, Zuhr O, Wachtel H, Bolz W, Huerzeler M. Tissue alterations after tooth extraction with and without surgical trauma: a volumetric study in the beagle dog. J Clin Periodontol. 2008;35(4):356-63. https://doi.org/1 0.1111/j.1600-051X.2008.01209.x.

22. Fickl S, Zuhr O, Wachtel H, Stappert CFJ, Stein JM, Hürzeler MB. Dimensional changes of the alveolar ridge contour after different socket preservation techniques. J Clin Periodontol. 2008:35(10):906-13. https://doi.org/10.1111/ j.1600-051X.2008.01305.x.

23. Jung RE, Siegenthaler DW, Hammerle $\mathrm{CH}$. Postextraction tissue management: a soft tissue punch technique. Int J Periodontics Restorative Dent. 2004;24(6):545-53.

24. Ten Heggeler JM, Slot DE, Van der Weijden GA. Effect of socket preservation therapies following tooth extraction in non-molar regions in humans: a systematic review. Clin Oral Implants Res. 2010;22:779-88.

25. Chen ST, Wilson TG, Hammerle CF. Immediate or early placement of implants following tooth extraction: Review of biologic basis, clinical procedures, and outcomes. Int J Oral Maxillofac Implants. 2004;19:12-25.

26. Amler $\mathrm{MH}$. The time sequence of tissue regeneration in human extraction wounds. Oral Surg Oral Med Oral Pathol. 1969;27(3):309-18. https://doi.org/1 0.1016/0030-4220(69)90357-0.

27. Jeschke MG, Sandmann G, Schubert T, Klein D. Effect of oxidized regenerated cellulose/collagen matrix on dermal and epidermal healing and growth factors in an acute wound. Wound Repair Regen. 2005;13(3): 324-31. https://doi.org/10.1111/j.1067-1927.2005.130316.x.
28. Crespi R, Capparé P, Crespi G, Gastaldi G, Gherlone E. Bone-level changes around delayed dental implants in previous large bone defects filled with reactive soft tissue after extraction: a cone beam computed tomography study. Int J Oral Maxillofac Implants. 2016;31(6):1429-34. https://doi.org/1 $0.11607 /$ jomi.4739.

29. Bruschi GB, Crespi R, Capparè P, Grande N, Bruschi E, Gherlone E. Radiographic evaluation of crestal bone levels of delayed implants at medium-term follow-up. Int J Oral Maxillofac Implants. 2014;29(2):441-7. https://doi.org/10.11607/jomi.3254.

30. Tawil G. Peri-implant bone loss caused by occlusal overload: repair of the peri-implant defect following correction of the traumatic occlusion. A case report. Int J Oral Maxillofac Implants. 2008;23(1):153-7.

31. Serino G, Biancu S, lezzi G, Piattelli A. Ridge preservation following tooth extraction using a polylactide and polyglycolide sponge as a filler: a clinical and histological study in humans. Clin Oral Implants Res. 2003;14(5):651-8. https://doi.org/10.1034/j.1600-0501.2003.00970.x.

\section{Publisher's Note}

Springer Nature remains neutral with regard to jurisdictional claims in published maps and institutional affiliations.

\section{Submit your manuscript to a SpringerOpen ${ }^{\circ}$ journal and benefit from:}

- Convenient online submission

- Rigorous peer review

- Open access: articles freely available online

- High visibility within the field

- Retaining the copyright to your article

Submit your next manuscript at $\boldsymbol{\nabla}$ springeropen.com 